\title{
SOBRE CONSTRUCTIVISMO MORAL: NECESIDAD DE UNA AXIOGRAFÍA EMPÍRICA
}

\author{
Fernando Lolas Stepke \\ Profesor Titular, Facultad de Medicina \\ Director, Programa Regional de Bioética OPS/OMS \\ Universidad de Chile
}

\author{
Correspondencia:Providencia 1017, Piso 7 \\ Santiago de Chile \\ E-mail: lolasf@chi.ops-oms.org
}



Acta Bioethica 2000; año VI, $\mathrm{n}^{\circ} 2$

\section{SOBRE CONSTRUCTIVISMO MORAL: NECESIDAD DE UNA AXIOGRAFÍA EMPÍRICA}

Fernando Lolas S.

\section{Resumen}

Este trabajo presenta una aproximación al proceso de construcción valórica tomando como fundamento el lenguaje natural, propio del mundo vital. Se sostiene que este lenguaje refleja las concepciones antropológicas implícitas y explícitas de una comunidad. Trazando un paralelo entre la atribución de significado técnico a las palabras en las tecnociencias, la construcción del léxico emocional y el lenguaje valórico, se atribuye a la deliberación y el diálogo, como herramientas bioéticas, la misión de incrementar el constructivismo moral de las sociedades pluralistas y ampliar sus potencias creativas de opciones. Ello no implica un relativismo moral, pero sugiere la necesidad de contextualizar los preceptos y principios y estudiar empíricamente las formas en que se articulan los dilemas y se proponen soluciones. Se proponen algunas líneas de desarrollo para una axiografía empírica con base en el lenguaje como legítimo componente de estudios sociales en bioética

Palabras clave: Constructivismo, Axiografía, Lenguaje, Antropología.

\section{Resumo}

Este trabalho apresenta uma aproximação ao processo de construção valórica tomando como fundamento a linguagem natural, própria do mundo da vida. Sustenta-se que esta linguagem reflete as concepções antropológicas implícitas e explícitas de uma comunidade. Traçando um paralelo entre a atribuição de significado às palavras nas tecnociências, a construção de vocábulos emocionais e a linguagem valórica, utiliza-se a deliberação e o diálogo como ferramentas bioéticas na busca de incrementar o construtivismo moral das sociedades pluralistas ampliando as possibilidades criativas de opções. Isto não implica num relativismo moral, mas sugere a necessidade de contextualizar os preceitos e princípios, assim como estudar empiricamente as formas em que se articulam os dilemas e nas soluções propostas. Propõem-se algumas linhas de desenvolvimento para uma axiografia empírica com base na linguagem como componente legítimo dos estudos sociais em bioética.

Palavras chaves: Construtivismo, Axiografia, Linguagem, Antropologia. 


\begin{abstract}
This paper presents an approach to the process of valoric construction based on natural language, as characteristic of the world of life. It si suggested that this language reflects explicit and implicit anthropological conceptions within a given community. Drawing a parallel between attribution of meaning to words in the technosciences, the establishment of emotional lexica and valoric language, deliberation and dialogue -bioethical toolsare charged with the task of increasing moral constructivism in pluralistic societies and widening their creative options. This does not imply moral relativism but it points out the need to contextualize precepts and principles and to empirically study the forms in which dilemmas are articulated and solutions proposed. Some lines of development for a language-based empirical axiography are proposed as a legitimate component of social studies in bioethics.
\end{abstract}

Key words: Constructivism, Axiography, Language, Anthropology.

\section{Résumé}

Ce travail présente une approximation au processus de construction des valeurs en prenant comme fondements le langage naturel, propre du monde vital. Il soutient que ce langage reflète les conceptions implicites et explicites d'une communauté. En faisant un parallèle entre l'attribution du sens technique aux mots dans les technosciences, la construction du lexique émotionnel et le langage des valeurs il soutient qu'il est possible d'attribuer à la délibération et le dialogue, comme outils bioéthiques, la mission d'augmenter le constructivisme moral des sociétés pluralistes et étendre leurs facultés créatrices d'options. Ceci n'implique pas un relativisme moral, mais suggère le besoin de contextualiser les préceptes et les principes ainsi que d'étudier empiriquement la facon dont les dilemmes sont articulés et des solutions sont proposées. Différentes lignes de développement sont proposées pour une axiographie empirique basée dans le langage comme composant légitime des approches sociales en bioéthique.

Mots clés: Constructivisme, Axiographie, Langage, Anthropologie. 


\section{EI lenguaje y la realidad}

Un concepto puede quedar descrito como un acto del entendimiento que hace concordar una percepción del mundo con una palabra. Tal definición, adoptada de Baltasar Gracián ${ }^{i}$, sugiere que el concepto, en tanto componente de la lengua natural, semeja un alvéolo vacío en el cual la experiencia depositará la savia de sus innumerables matices. Ortega y Gasset destacaba que desarrollar conceptos es, efectivamente, una forma de generar concepciones del mundo.

La noción de constructo captura aún mejor que concepto la idea de artificio y de invención, la función poiética del lenguaje. Éste no sólo reproduce el mundo. Lo crea y transforma. El ámbito del mundo sensible y operable es el ámbito del lenguaje activo. Los constructos, en tanto operaciones posibles, son auténticas invenciones y rigen, dirigen y moldean la vida de las personas.

De la masa semántica de una lengua, la mirada especializada o experta recorta segmentos, la fragmenta en formas características, le imprime modulaciones particulares. Los ademanes y gestos, que todo lenguaje en última instancia atesora y codifica, se formalizan y solidifican. Con la precisión ganada se pierde libertad. Las connotaciones acotadas del término técnico, el empobrecimiento de sus potencialidades expresivas, son parte del precio pagado por la exactitud.

El carácter convencional de la terminología tecnocientífica es una de sus marcas más distintivas. Alfred North Whitehead observaba que los científicos comparten con Humpty Dumpty la posibilidad de nominar como les place los hechos de la experiencia y los datos sensoriales. Al nominar se construye. Este constructivismo adopta muchas

\footnotetext{
${ }^{i}$ Gracián (1601-1658) dedica a este asunto algunos pasajes de su tratado Agudeza y Arte de Ingenio.

ii Los estudios de Bruno Latour son, a este respecto, de excepcional valor.
}

formas. Las radicales suponen que todo el corpus de la ciencia es una construcción artificiosa. Las moderadas suponen la coexistencia de interacciones que originan productos nuevos. Por ejemplo, la preparación de informes científicos (papers) es un proceso social con recurrencias, avances y retrocesos. En las múltiples versiones que se producen se va configurando la "realidad", la cual más que reflejarse en el producto, es "conjurada" por él. Es demostrativo a tal efecto el modo cómo se citan los trabajos del propio grupo y los de grupos afines o rivales $^{\mathrm{ii}}$. Los "hechos" son "creados" de la lectura de instrumentos, la contrastación de experiencias sensoriales y la argumentación con pares ilustrados. Queda como realidad aquello en lo cual la comunidad de expertos no discrepa para interpretar los "datos". Esa ausencia de discrepancia constituye la realidad aceptada. $\mathrm{Y}$ es fruto del procedimiento, no revelación de la naturaleza.

\section{Sobre el lenguaje valórico y el mundo vital}

No es difícil comparar esta simplificada visión de la epistemología de las ciencias empíricas con lo que ocurre en el ámbito del mundo vital (Lebenswelt). Este ámbito preconceptual pero postsensorial incluye la totalidad de las experiencias, incluso aquellas no verbalizadas, no verbalizables o fuera de la conciencia. Es la "materia prima" para los espacios semánticos de los discursos específicos, científicos, políticos o técnicos. Este mundo vital es una "presencia" que se transforma en dato, prueba o información por la violencia encasilladora y recortadora, propia de la praxis poiética del experto.

Una importante mutación sufre el lenguaje. El significado de los términos del discurso especializado deriva de un metadiscurso de construcciones. Un término del lenguaje técnico sólo tiene valor en el contexto de ese metalenguaje de constructos. Su significado no es intrínseco, no reside en él. Es 
producto de la posición que ocupa el término en el conjunto del léxico especial. En el lenguaje natural, en cambio, la polisemia de los términos hace que muchos significados sean posibles, tantos como contextos de interpretación. No hay una "lectura canónica", única e indivisa, que pueda asegurar unívoca y total inteligibilidad de los textos del lenguaje natural. Es una de las claves de la literatura de ficción. Sus efectos no dependen solamente del mensaje sino también del contexto.

El léxico de los afectos ilustra el efecto ordenador del metalenguaje de constructos teóricos. Determinadas expresiones son asignadas a una categoría por el uso del hablante natural o por la práctica social que codifican y transmiten. Muchas formas de análisis del contenido verbal se basan en categorías descriptivas, cuya conformación, de proceso inductivo, luego se revierte y se hace garante del significado de las expresiones ${ }^{\mathrm{iii}}$. Las relaciones entre estructuras psíquicas y estructuras de comunicación es casi un tópico en las disciplinas psicológicas (1).

Si estas nociones se trasladan al lenguaje valórico es posible plantear una aproximación empírica a su estudio. Sin necesidad de fundar una "estimativa" como base de una ciencia de los valores, estos, en tanto expresiones verbales, son universales de sentido en la experiencia interpersonal que norman y regulan procesos cognoscitivos, afectivos e instrumentales. Por la existencia de valores es el lenguaje natural un depositario más o menos fiel de las prácticas sociales. Si bien cabe el engaño y la falsedad, como en todo lenguaje polisémico, sus relaciones con el comportamiento y la relación interpersonal fundamentan emplear el diálogo en la deliberación, la argumentación y el debate. Tales vinculaciones permiten reconstruir el "hablante valórico", la "imagen de hom-

iii La extensa literatura sobre análisis de contenido y análisis del discurso no puede, en justicia, comentarse en este lugar. bre" o, como podría decirse, la antropología implícita en el discurso natural (2). Esta tarea debe usar los recursos y presentar los resultados propios de una empiria ordenada, a fin de rescatar para el diálogo bioético su carácter de herramienta social.

\section{Constructivismo moral y bioética dialó- gica}

En sus formas actuales el constructivismo es un sistemismo dinámico (3). Esto significa que a las propiedades del sistemismo clásico -la complementariedad, la característica de ser la totalidad más que suma de las partes, la organización en jerarquías emergentes- se agrega un factor diacrónico. Las realidades no son inmutables; se constituyen mediante procesos sociales. Por ejemplo, la díada médico-paciente es una construcción sistémica cuya rotundidad o plenitud depende de lo logrado del encuentro y de cómo se mantiene. La "conciencia de valor en el hacer", según la acertada expresión de Paul Christian, está expuesta a mutaciones (4). Hay múltiples valores involucrados en toda transacción social. Cuando tales valores exigen esfuerzo e intelección (askesis y mathesis) pueden considerarse virtudes, plenitudes propias de objetos, personas, situaciones.

Una de las tareas de la bioética es contribuir al constructivismo moral de las sociedades democráticas (5). Expandir la creación de lenguajes morales. Ello no es relativismo. Es reconocer que todo principio es modulado por la comunidad en la que se manifiesta. Tarea de los cuerpos sociales es deliberar sobre las mejores formas de concretar los principios universales para mejor servir a las finalidades comunitarias.

Muchas normas que constituyen la "moralidad común" del mundo de la vida son de carácter implícito, no reflexivo. Simplemente se actúa por alguna forma de "sensación" sobre lo correcto o lo incorrecto. Aunque 
siempre se entabla un diálogo con la propia conciencia, con los usos de la comunidad, con las tradiciones religiosas, con los personajes carismáticos y ejemplares, la fundamentación racional está a menudo ausente y obliga al desarrollo disciplinario que se confía a filósofos y otros expertos. A menudo, conductas semejantes reconocen fundamentaciones tan dispares, que explicitarlas es fuente de controversia y duda. "Desenmascarar lo real" en el comportamiento moral es, exactamente como en la exploración psicoanalítica del inconsciente, una tarea no trivial, a la que debe entregarse esfuerzo y tiempo. Un proyecto del Centro Interdisciplinario de Estudios en Bioética de la Universidad de Chile, explorando las tradiciones monoteístas reflejadas en los textos fundacionales y canónicos, permitió desentranar la causa de resistencias incomprensibles hacia prácticas sanitarias técnicamente correctas en el plano de la sexualidad (6). Un trabajo de esa naturaleza es comparable a una "piedra Rosetta" que permite descifrar el jeroglífico de las creencias que se tienen sin saber que se las tiene. Insustituible papel cabe aquí a los investigadores de las culturas, los cuales, armados de sensibilidad filosófica, pueden contribuir a legitimar prácticas y hacer transparente la toma de decisiones en materias de interés común.

Esta labor de des-cubrimiento de lo cotidiano y de las inercias del hábito moral es indispensable para dotar de viabilidad empírica a las medidas propias del trabajo investigativo, diagnóstico y terapéutico.

\section{La norma ética y su contenido empírico}

Toda teoría de la decisión ética en contextos específicos debe considerar los fundamentos de una teoría general de la conducta social. De esta pueden derivarse principios analíticos que den contenido empírico a los conceptos formales de la ética y los aproximen a la práctica de la moralidad pre- reflexiva o "común". La construcción de tal teoría general de la conducta social exige la recolección de información empírica, sin que ello implique una negación del plano de fundamentación discursiva que exige la reflexión filosófica ulterior.

El problema del contenido empírico de la norma ética y su admisión o rechazo por parte del agente moral ha sido abordado en diversos contextos. Los "métodos de decisión en ética clínica"(7)consideran los aportes de la teoría del grupo, de la psicología social y de la teoría general de la información. La elaboración de pautas o "instrumentos psicométricos" ha llevado a proponer "axiogramas", esto es, registros objetivos de modelos de toma de decisiones, racionales o espontáneos, en todo semejantes a un examen clínico (hemogramas, cintigramas, etc...). Un ejemplo es el Protocolo de Bochum para práctica ético-médica (8), que se presenta como una guía sencilla para la investigación. Los avances de la técnica de entrevista y la aplicación de métodos de análisis del discurso permiten esperar importantes desarrollos. La preeminencia de las metódicas biológicas ha llevado a desestimar la contribución del examen de la conducta verbal a la práctica adecuada de la medicina. No obstante, la experiencia clínica y de planificación sugiere que la praxis (fusión de práctica y teoría) está guiada tanto por estimativas manifiestas como por factores encubiertos procedentes del entorno social y la subjetividad individual. La corriente del "emotivismo ético" ha insistido en aspectos valiosos en esta dirección, desvirtuados al extremar la posibilidad del relativismo normativo. La discusión de estos contrastes y aporías es substantivo componente de la muchos textos bioéticos $(9,10)$. Tema explícito o implícito en el trabajo de los Comités de ética.

En la atención sanitaria los temas bioéticos han sido formulados y discutidos en el registro de los "derechos" y en el de las "virtudes”. Más que la autonomía, núcleo temá- 
tico de la bioética estadounidense, en América Latina se ha privilegiado la discusión sobre equidad, justicia, acceso a recursos de salud, calidad de estos, derechos de los pacientes y práctica de la medicina en los contextos estatal y privado. Es significativo que deba recalcarse el papel de los sujetos en la determinación de sus opciones de salud, como en el documento base para la reunión sobre Reestructuración de la Atención Psiquiátrica en las Américas, convocada por la Organización Panamericana de la Salud en 1990 y origen de una importante declaración (11). La profesión médica latinoamericana está apenas consciente de las declaraciones internacionales y los protocolos de protección de los sujetos en investigación y tratamientos experimentales. Algunos colegios profesionales asumen un papel de defensa de los derechos de pacientes y profesionales y declaran frecuentemente su intención de mantener la equidad y el respeto a la autonomía. Ya era evidente esta postura en un estudio conducido hacia fines de los ochenta (12). No obstante, estudios empíricos sobre conocimiento de la normativa internacional, principios de calidad de atención, satisfacción de usuarios e impacto de la accesibilidad real y potencial a servicios son escasos y a menudo instrumentalizados con alguna finalidad puramente administrativa. Las evaluaciones realizadas por servicios públicos y privados de salud suelen centrarse en aspectos operacionales y aspiran a convencer a los usuarios de determinadas cualidades. A menudo, su finalidad no es crítica sino aprobatoria, confundiendo funciones con fines y medios con metas. De allí la necesidad de una propuesta que independientemente de factores operativos y administrativos explore la hipótesis de que la calidad de la atención es función de la satisfacción de usuarios y prestadores y esta, a su vez, de la concordancia o discordancia de la competencia práctica con la normativa general. Esto es especialmente relevante en el campo de la psiquiatría, cuya percepción por parte de médicos y público es particularmente variable.

Un trabajo de axiografía empírica debe poner de manifiesto los procesos por los cuales se construyen, legitiman y adoptan decisiones valóricas y juicios morales. Los filósofos profesionales suponen que se debate y luego se juzga, pero en la práctica el juicio antecede a todo debate y la virulencia de los ataques contra actores y agentes sociales que sostienen opiniones discrepantes suele depender de un insuficiente conocimiento de la axiografía empírica y del constructivismo moral que es parte del diálogo social.

\section{Axiografía empírica y la construcción de la salud}

La promoción y la protección de la salud se enfrentan en la actualidad a desafíos de muchos órdenes.

Uno de los más urgentes es la participación efectiva de las comunidades a las que tales tareas se dirigen. Ella sólo es posible a condición de superar barreras de lenguaje, perspectiva y contexto, que tradicionalmente se espera sean motivo de esfuerzos educativos. Pese a existir amplio consenso, no se pondera la dificultad que implica el pluralismo de las sociedades contemporáneas.

Este pluralismo no es solamente de informaciones y conocimiento. Es también de convicciones y creencias. Como advierte Tristram Engelhardt, las sociedades contemporáneas están compuestas por grupos de "extraños morales" que recíprocamente ignoran sus respectivas visiones de mundo o, cuando las conocen, tienden a no compartirlas en tanto que principios fundantes de sus comportamientos.

No siempre son obvias o evidentes las diferencias. Hay muchas distinciones que no son auténticas diferencias. A veces, las diferencias son exaltadas o reducidas al tenor de cambios sociales. 
Particular importancia revisten las diferencias valóricas influidas por creencias religiosas. Tienden a incorporarse a los usos sociales de manera sutil y no reconocida ni siquiera por quienes las profesan. La arqueología de lo cotidiano revela presencias que deben ser descubiertas y examinadas. La razón de muchas costumbres y usos sociales permanece oculta hasta que la investigación, tomando distancia de lo que "siempre ha sido asî", interroga el substrato creencial y valórico en busca de claves y pistas que expliquen el comportamiento.

La relevancia de tal indagación para la promoción, la protección y el mejoramiento de la salud es evidente. Especialmente si, como hemos señalado, en alguna de sus etapas estas tareas involucran procesos educativos. Educar no es transmitir informaciones, ni siquiera compartir vocabularios o actitudes. Es permitir que las personas participen activamente en el diálogo societario a través del conocimiento y del lenguaje. Saber es participar y la educación es una forma de hacer-saber para integrar las personas a la sociedad.

Aunque no cabe dudar que los procesos formales de instrucción y de información son importantes, gran parte del proceso educativo discurre por fuera del aula y del trato con los expertos. Cuantificar el aporte de la educación formal a forjar comportamientos ha sido siempre difícil. Los educadores y los técnicos suelen sobreestimar su propia contribución. Los instrumentos para medir impacto privilegian el tipo de resultado que sus métodos permiten y anticipan, pero son inadecuados para valorar el componente informal. Cabe suponer que el cambio conductual es una compleja amalgama de trabajo experto, metodología docente, información específica, creencias, prejuicios y experiencias individuales. A menudo, una convicción enraizada en las costumbres ejerce soterrada influencia y modula imperceptiblemente la información recibida y su uso.

En el proceso de educar para la salud es indispensable conocer el substrato individual y colectivo sobre el cual la información científica se insertará. Se tilda de "creencias" aquellas certidumbres no avaladas por los datos científico-técnicos y de "informaciones" las derivadas de la ciencia oficial. Pese a su origen, algunas creencias populares han sido fuente de inspiración para el trabajo científico. La investigación biopsicosocial reconoce cada vez con mayor relieve la impronta de las creencias en el bienestar y la salud.

\section{Algunas propuestas de análisis}

El conocimiento del substrato creencial y valórico es un proceso que exige acuciosidad metódica, neutralidad observacional e imparcialidad en el juicio. El componente etnográfico y descriptivo exige pureza conceptual y diseño pulcro, además de las tradicionales aptitudes que se adquieren y cultivan con el entrenamiento en las ciencias sociales. Estimular estudios de esta clase es un imperativo en el campo de la salud, considerando que el lenguaje de la oferta de servicios tiende a disociarse del lenguaje de la demanda. Cuando no se responde a las expectativas de los usuarios hay frustración, insatisfacción y crisis de los sistemas de cuidado de la salud. Aunque éstas sean crónicas y afecten a todos los sistemas que responden a demandas sociales, puede prevenirse la insatisfacción conociendo sus causas. El divorcio entre expectativa y oferta se produce especialmente en los aspectos más tecnificados de la atención sanitaria, en los que la racionalidad científica tiende a ser hegemónica y excluyente (13). Al ignorar los orígenes de la demanda, los sistemas técnicos entran en una dinámica propia de autorreproducción sin referencia a la necesidad que los creó. Muchas veces se perpetúan, en el seno mismo de la racionalidad científica, creencias irracionales y juicios valóricos no examinados. Es una razón adi- 
cional para fomentar el estudio del lenguaje valórico natural, propio del mundo vital.

Aparte de la necesaria investigación social de tipo descriptivo, es necesario conocer las fuentes de las creencias. Sistemas de pensamiento, ideologías y religiones deben considerarse como origen de prácticas y comportamientos en relación con la salud al diseñar programas educativos. Los sistemas de creencias pueden cambiar de modo impensado y afectar la recepción y el uso de los mensajes. Entre los mismos expertos se perpetúan convicciones inadecuadas e infundadas, como pensar que por declararse católica la mayoría de una nación se puede anticipar su comportamiento. Por otro lado, erróneamente se atribuyen al magisterio de la iglesia católica algunas directrices que a veces no proceden del cristianismo sino de fuentes más antiguas, como el judaísmo o el animismo.

Se desprende la conveniencia de un conocimiento cabal de la tradición y la doctrina de religiones influyentes en el continente americano. Junto con el estudio empírico de los procesos sociales, que tal conocimiento complementa, puede obtenerse un cuadro del substrato humano sobre el cual se ejercerá la acción educativa, la promoción, la protección y el mejoramiento de la salud. Un estudio de las fuentes textuales y de las tradiciones orales es imprescindible. Su presentación ordenada y comentada constituye una suerte de "piedra Rosetta" que permite decodificar las reacciones de la comunidad frente a la labor técnica y anticipar el éxito o el fracaso de las iniciativas en educación y salud.

Eliminar las inexactitudes con que se presentan y comunican creencias y valores no es tarea simple. Tampoco basta la mera exposición. En realidad, la interacción entre creencia, conocimiento, coyuntura sociopolítica y circunstancia histórica produce un resultado caleidoscópico, especialmente en el continente americano, auténticamente criollo por las mezclas de razas, geografías y tradiciones.
Un trabajo de esta índole es siempre circunstancial y provisorio. Exige estudios lingüísticos, teológicos, filosóficos y metodológicos que, como en otras ramas de las humanidades, se perfeccionan en la aplicación a temas concretos (14). Los expertos en educación sanitaria y quienes trabajan en contacto directo con las poblaciones observarán cuánto aumenta su sensibilidad frente a las resistencias y dificultades conocer el trasfondo religioso y valórico de los comportamientos (15). Como señalamos, ni los mismos individuos saben por qué reaccionan frente a algunos temas o qué defensas inconscientes hay frente a otros. El discurso valórico y de la religiosidad debe ser integrado a las perspectivas prácticas sobre salud y enfermedad. Para una adecuada intervención, desentrañar la antropología implícita que ese discurso revela ya no puede considerarse un lujo: es una imposición del cambiante escenario de la vida social.

\section{Referencias}

1. Lolas F. Sobre el lenguaje emocional. Lenguas Modernas 1994; 21:169-78.

2. Lolas F. La perspectiva psicosomática en medicina. $2^{\mathrm{a}}$ ed. Santiago de Chile: Editorial Universitaria; 1995.

3. Rusch G, Schmidt S.J, (eds). Konstruktivismus in psychiatrie und psychologie. Frankfurt/M.: Suhrkamp Verlag; 2000.

4. Christian P. Medicina antropológica. Santiago de Chile: Editorial Universitaria; 1997.

5. Lolas F. Bioética y antropología médica. Santiago de Chile: Mediterráneo; 2000.

6. Tapia Adler A, Moreno J, Escríbar A. Valoración de la vida y de la sexualidad en las fuentes judeocristianas y en el magisterio de la Iglesia. Manuscrito Centro Interdisciplinario de Estudios en Bioética, Santiago de Chile: Universidad de Chile, 1999.

7. Gracia D. Métodos de decisión en ética clínica. Madrid: EUDEMA; 1991.

8. Sass HM, Viefhues H. Bochumer arbeitsbo- 
gen zur medizinethischen praxis: medizinethische materialien. Bochum: Zentrum für Medizinische Ethik; 1987.

9. Beauchamp P, Childress J. Principles of biomedical ethics. $3^{\mathrm{a}}$ ed. New York: Oxford University Press; 1994.

10. Engelhardt T. The foundations of bioethics. New York: Oxford University Press; 1995.

11. Marín U, Lolas F, Kreimer O, Fuenzalida H. Reestructuración de la atención psiquiátrica. Aspectos éticos y jurídicos. Documento base para la Conferencia Regional para la Reestructuración de la Atención Psiquiátrica. Caracas: 1990.
12. Lolas F. Bioética en Chile. Actualidad y perspectivas. Boletín de la Oficina Sanitaria Panamericana 1990; 108: 536-41.

13. Lolas F. On the goals of medicine: reflections and distinctions. In: Hanson M, Callahan D, (eds). The goals of medicine. Washington, D.C.: Georgetown University Press; 1999. p. 216- 20.

14. Lolas F. Medical praxis: an interface between ethics, politics, and technology. Social Science and Medicine 1994; 39:1-5.

15. Lolas F. Desafíos de la bioética en el contexto latinoamericano. Medicina al Día 1994; 3:81-4. 